\title{
KONSEP PEREMPUAN DI MINANGKABAU: Analisa Sosiolinguistik Tentang Konsep Bundo Kanduang \\ $\operatorname{Irwan}^{1}$ \\ irwanmalinbasa@gmail.com
}

\begin{abstract}
This article discussess about the concept of woman in Minangkabau culture. Untill now people are still in doubt about the meaning of the word of Bundo Kanduang. The meaning of Bundo Kanduang which have been kept into the mind of most people is "a queen" or "a king" who ever had a good position in Pagaruyung kingdom. She was described as a very perfect woman. But in fact, that story was not really true because it was found in some Minangkabau manuscripts that Bundo Kanduang means a concept of woman in Minangkabau, not a real woman which ever occupied a kingdom in $13^{\text {th }}$ century.
\end{abstract}

Kata Kunci: Bundo Kanduang, Konsep, Minangkabau, Sosiolinguistik

\section{PENDAHULUAN}

Kata bundo kanduang secara umum dimaknai sebagai perempuan di Minangkabau. Selama ini persepsi masyarakat tentang bundo kanduang adalah seorang perempuan yang merupakan gambaran dari seorang raja Pagaruyung di zaman dahulu. Ketika itu bundo kanduang adalah sosok pemimpin kerajaan yang bijaksana, adil dan malah disebutkan dalam sejarah bahwa kerajaan Pagaruyung ketika dipimpin oleh bundo kanduang tidak memiliki tentara. Dapat dikatakan bahwa bundo kanduang adalah raja yang tidak suka berperang dan tidak suka kekerasan. Dia menginginkan negara yang aman dan tentram serta masyarakatnya adil dan makmur. Bak kata pepatah, padi masak jaguang maupiah, taranak bakambang biak. Nagari aman santoso, rakyatnyo rukun dan damai. Tetapi benarkah demikian?

Sayuti (2009) mengatakan bila ditinjau dari terminologi istilah yang dipakai dalam menyebutkan lawan jenis laki-laki ini cukup bervariasi. Ada yang menyebut wanita, perempuan, Bundo kanduang. Wanita menurut bahasa sangsekerta berasal dari kata wanit yang artinya merangsang birahi nafsu, sedangkan perempuan berasal dari kata empu yang artinya ratu rumah tangga.

\footnotetext{
${ }^{1}$ Penulis merupakan Ketua Komunitas Nagari Tuo Pariangan, Desa Terindah di Dunia
} 
Padusi berasal dari bahasa Majusi yaitu Padu + si, yang artinya padu = tempa, dan kata $s i$ artinya $=$ disini . Berarti dapat diartikan secara lengkap dengan tempa disini. Cerita ini terkait dengan kisah Adam dan Hawa. Bundo kanduang, berasal dari kata bundo yang artinya ibu, sedangkan kata kanduang artinya adalah sejati. Berarti ibu sejati.

Sampai saat ini di setiap organisasi atau perkumpulan yang beranggotakan perempuan sering disebut bundo kanduang. Isteri pejabat, ketua PKK dan jargonjargon yang berhubungan dengan perempuan selalu disebut bundo kanduang. Fenomena seperti itu adalah pengaruh dari bundo kanduang yang pernah menjadi raja tersebut. Sampai saat ini Bundo kanduang sering dijadikan lambang isteri pejabat. Kalau suaminya seorang bupati misalnya, maka isteri bupati itu otomatis menjadi bundo kanduang di kabupaten tersebut. Saya berani mengatakan bahwa ini adalah pemahaman yang salah! Kita sudah salah jalan dalam memaknai bundo kanduang selama ini. Tidak ada satu aturanpun dalam adat Minangkabau yang mengatakan bahwa isteri penghulu atau ninik mamak sekalipun adalah ex-officio sebagai bundo kanduang!

Di Minangkabau perempuan sangat dimuliakan sehingga kemuliaan itu dituangkan dalam naskah kuno berupa catatan-catatan bersejarah yang mesti kita pelajari dan kita kaji. Dalam sebuah naskah kuno yang ada di Pariangan yang penulis salin dari almarhum A.H. DT. Rangkayo Sati dijelaskan bagaimana konsep bundo kanduang tersebut. Gambarannya adalah bahwa bundo kanduang itu bukanlah jabatan, melainkan sifat atau watak dari perempuan Minang yang ideal ketika itu. Bundo kanduang bukanlah isteri penghulu. Bundo kanduang bukanlah posisi ketua-ketua perempuan. Bundo kanduang bukanlah kumpulan perempuan dalam sebuah organisasi.

Bahasa yang ada dalam naskah itu pernah menjadi tuturan/ujaran bagi masyakat Minangkabau baik secara formal maupun secara informal. Ketika sebuah tuturan pernah ada dalam suatu komunitas maka makna tuturan itu bisa dianalisa dengan ilmu sosiolinguistik. Sosiolinguistik adalah salah satu cabang ilmu bahasa yang mengkaji bagaimana bahasa itu digunakan dalam masyarakat. 
Chaer (2012:2) mengatakan bahwa sosiolinguistik adalah bidang ilmu antar disiplin ilmu yang mempelajari bahasa dalam kaitannya dengan penggunaan bahasa itu dalam masyarakat. Dalam hal ini konsep berupa tuturan adalah bagian dari bahasa pula sehingga tuturan itu bisa dianalisis dengan ilmu sosiolinguistik.

Sedangkan Fishman dalam Sumarsono (2007:2) menyatakan bahwa sosiolinguistik menyoroti keseluruhan masalah yang berhubungan dengan organisasi sosial perilaku bahasa, tidak hanya mencakup pemakai bahasa saja, melainkan juga sikap-sikap bahasa, perilaku terhadap bahasa dan pemakai bahasa. Sosiolinguistik memandang bahasa sebagai sistem sosial dan sistem komunikasi.

Jadi seluruh konsep yang tertulis dalam naskah kuno itu bisa dianalisis maknanya dan diuraikan sesuai dengan kaidah-kaidah ilmu bahasa sehingga dapat dipahami maknanya. Salinan tuturan itu nantinya bisa dipedomani, dipelajari dan dijadikan acuan tatanan hidup, bukan hanya sebagai penghias pidato atau pemanis cerita saja.

\section{KONSEP PEREMPUAN DI MINANGKABAU}

Dalam naskah kuno Minangkabau disebutkan bagaimana konsep perempuan yang baik dan tidak baik. Perempuan yang baik digambarkan sebagai bundo kanduang dan perempuan yang tidak baik digambarkan sebagai Simarewan. Di bawah ini konsep bundo kanduang tersebut:

Baa bana nan bundo kanduang?

Sungguahpun inyo parampuan

Inyo basipaik laki-laki

Apo nan tidak ditaruahnyo

Salain bulan jo matohari

Rang mudo salendang dunia

Rang kayo suko dimakan

Baragiah di nan tidak 
Barimaik di nan ado

Lai pantang diagiah

Indak bapantang disambunyikan

Pahamnyo aluih manakuak budi

Tau dikieh kato manyandiang

Kok datang jo tangih dipujuaknyo

Kok datang jo galak dijujainyo

Tak ameh bongka diasah

Tak kayu janjang dikapiang

Tak aia talang dipancuang

Manah nan jangan usak luak

Pusako nan jangan rusak sumbiang

Nak jan nyo rusak namo jo bangso

Sedangkan konsep perempuan yang tidak baik atau Simarewan digambarkan sebagai berikut ini (Jamil, 2015):

Mano padusi Simarewan

Bapaham sarupo gatah cayia

Iko elok, iko katuju

Bak cando pimpiang di lereang

Baparangai sarupo pucuak aru

Kamano angin inyo ka kian

Alun dijujai inyo lah galak

Alun diimbau inyo lah datang

Nan bak balam talampau jinak 
Basipaik bak lipeh tapanggang

Umpamo caciang kapanasan

Tagisia labiah bak kanai

Kok tumbuah bagaua jo laki-laki

Banyak galak dari kecek

Banyak kucikak jo kucindan

Malu jo sopan tak bapakai

Ereang jogendeang tak paguno

Nan bak katidiang tangga bingkai

Nan bak payuang tangga kasau

Elok baso nan tak manantu

\section{ANALISA TUTURAN BUNDO KANDUANG}

Dari konsep tersebut di atas dapat kita analisa secara sosiolinguistik. Bagaimana makna tuturan tersebut sehingga kita yang hidup di zaman sekarang bisa memaknai isi atau maksud konsep tersebut.

Baa bana nan bundo kanduang?

Sungguahpun inyo parampuan

Inyo basipaik laki-laki

Baris pertama dari kalimat di atas adalah sebuah pertanyaan yang betulbetul mengenai bundo kanduang itu. Seperti apa sosok bundo kanduang tersebut. Baris kedua bermakna meskipun bundo kanduang itu seorang perempuan tetapi dia bersifat seperti laki-laki. Artinya bundo kanduang adalah gambaran bahwa perempuan Minang itu harus tegar, tidak cengeng, mampu berdikari serta memiliki ketegaran jiwa. Perempuan Minang tidak boleh putus asa dalam menjalani kehidupan ini. Bak kata pepatah, patah kaki batungkek paruah. Artinya, ketika terjadi sesuatu kondisi yang sulit sekalipun perempuan Minang 
harus bisa berjuang menjalani hidup walaupun banyak beban yang akan ditanggung. Misalnya, dalam keluarga, ketika perempuan itu sudah memiliki anak dan tiba-tiba suaminya meninggal dunia atau tampek bagantuang bana nan lah hilang, maka dia harus menyingsingkan lengan baju untuk mencari nafkah demi menghidupi keluarga mereka. Perempuan Minang harus siap menghadapi segala kondisi.

Selanjutnya makna dan analisa dari bait berikut:

Apo nan tidak ditaruahnyo

Salain bulan jo matohari

Rang mudo salendang dunia

Rang kayo suko dimakan

Kalau diterjemahkan kedalam bahasa Indonesia maka keempat baris di atas berbunyi: apa yang tidak dimiliki oleh perempuan; selain bulan dan matahari, ketika masa mudanya dia mau berkorban untuk dunia, dia mau juga menikmati indahnya dunia sesuai dengan batas-batas yang wajar. Kalau dia orang kaya maka dia orang yang suka memberi antar sesama.

Pemahaman lebih lanjut tentang keempat baris tersebut adalah bahwa bundo kanduang sebagai perempuan Minang harus kaya, memiliki harta dan tidak boleh miskin. Apapun harus dia miliki walaupun serba sedikit. Tentu sesuatu itu harus dimiliki dengan cara-cara yang halal dan baik.

Selanjutnya makna dan analisa dari bait berikut:

Baragiah di nan tidak

Barimaik di nan ado

Lai pantang diagiah

Indak bapantang disambunyikan

Arti dari kalimat di atas adalah bundo kanduang harus memiliki sifat dermawan dan tidak boleh pelit. Meskipun harus dermawan seorang bundo 
kanduang juga tidak boleh boros dan menghambur-hamburkan uang yang sudah terkumpul. Dia harus pandai memilih dan memilah mana yang perioritas untuk kehidupannya. Namun ketika ada sanak saudara serta keluarga yang memang sangat membutuhkan bantuan dan dalam kondisi sulit mengharapkan bantuannya maka dia harus memberikan bantuan sesuai dengan kemampuan.

Begitu juga dalam hal menerima sesuatu. Ketika seorang bundo kanduang memiliki sesuatu namun tiba-tiba saja ada orang yang memberi sesuatu kepadanya tanpa sebab dan alasan yang jelas maka bundo kanduang harus memikirkannya matang-matang. Apa maksud seseorang memberinya? Apakah ada udang dibalik batu? Bundo kanduang harus berani menolak pemberian yang tidak jelas apalagi kalau dia sudah memiliki sesuatu itu. Bundo kanduang harus arif dalam memaknai sikap seseorang kepadanya.

Selanjutnya makna dan analisa dari bait berikut:

Pahamnyo aluih manakuak budi

Tau dikieh kato manyandiang

Kok datang jo tangih dipujuaknyo

Kok datang jo galak dijujainyo

Seorang bundo kanduang harus memiliki budi pekerti yang baik. Dia harus bisa bertutur kata yang baik, berlaku elok dan sopan. Dia tidak boleh berkata kasar kepada siapapun apalagi sampai menyakiti hati seseorang. Dia harus bisa memahami setiap maksud pembicaraan orang kepadanya. Dia harus bisa menangkap makna yang tersirat dari pembicaraan orang lain kepadanya.

Dalam menjalani kehidupan tentu tidak ada manusia yang lepas dari suka dan duka. Jika datang seseorang yang mengadu kepadanya dengan kesedihan maka dia harus pandai mencarikan jalan keluar dari suatu persoalan tersebut. Dia harus pandai menenangkan orang yang sedang gelisah yang dililit persoalan. Namun ketika datang orang-orang yang ingin berbagi cerita bahagia dengannya, dia juga harus bisa menjadi pendengar yang baik dan memberikan semangat kepada orang yang bercerita sehingga kegembiraan itu semakin menggelora. Dia 
harus bisa merasakan kebahagiaan yang dirasakan oleh orang-orang terdekatnya. Dia tidak boleh bersifat iri dan dengki terhadap kebahagiaan orang lain.

Selanjutnya makna dan analisa dari bait berikut:

Tak ameh bongka diasah

Tak kayu janjang dikapiang

Tak aia talang dipancuang

Ketika dalam kondisi sulit seorang bundo kanduang harus bersedia berkorban. Jika ada sanak saudara dalam kesulitan dan harus dibantu maka dia harus mengorbankan apa yang dia miliki untuk membantu saudaranya tersebut. Meskipun uang tidak punya pada saat itu, dia mungkin saja bisa menjual emasnya dan meminjamkan uang dari hasil penjualan emas tersebut kepada sanak keluarga yang membutuhkan itu.

Selanjutnya makna dan analisa dari bait berikut:

Manah nan jangan usak luak

Pusako nan jangan rusak sumbiang

Nak jan nyo rusak namo jo bangso

Maksud dari kata di atas adalah seorang bundo kanduang harus bisa menjaga amanah dari siapapun. Dia harus bisa menjaga setiap harta yang dipercayakan kepadanya demi menjaga harkat dan martabat dirinya dan keluarganya. Dia harus jujur dalam mengelola harta. Dia harus bisa membedakan mana yang harta warisan atau pusaka tinggi dan mana harta pencaharian dari suaminya atau hibah dari seseorang kepadanya jika ada.

Bundo kanduang harus bisa menjaga martabat keluarga, suku, kampung dan nagari tempat dia tinggal. Sebab sebagaimana kata orang bijak, jika perempuan itu rusak maka rusaklah sebuah bangsa dan jika perempua itu baik maka baik pulalah sebuah bangsa atau kaum. 


\title{
ANALISA TUTURAN PADUSI SIMAREWAN
}

Dari konsep padusi Simarewan tersebut di atas dapat kita analisa secara sosiolinguistik bagaimana makna tuturan tersebut sehingga kita yang hidup di zaman sekarang bisa memaknai isi atau maksud konsep tersebut.

Enam baris pertama adalah:

\author{
Mano padusi Simarewan \\ Bapaham sarupo gatah cayia \\ Iko elok, iko katuju \\ Bak cando pimpiang di lereang \\ Baparangai sarupo pucuak aru \\ Kamano angin inyo ka kian
}

Tiga baris pertama ini dapat kita artikan seperti apa padusi Simarewan tersebut yaitu memiliki paham seperti karet yang encer. Karet yang encer itu mudah melekat kemana mana. Dimana ada kawan maka dia akan menempel tanpa pandang bulu. Kata iko elok iko katuju artinya tidak memiliki pendirian yang kuat. Boleh juga disebut mata keranjang.

Sedangkan tiga baris kedua dapat diartikan perempuan simarewan itu adalah perempuan yang tidak berprinsip dalam hidupnya. Jika banyak orang mengatakan sesuatu itu baik maka dia akan ikut ikutan juga mengatakan baik, tetapi jika orang mengatakan yang baik itu buruk maka dia akan ikut serta juga mengatakan seperti itu. Dia hanya akan ikut kemauan dan kehendak orang ramai. Dia selalu dilamun gelombang kehidupan tanpa pernah bertahan dengan prinsip yang dia yakini benar.

Sedangkan enam baris kedua adalah:

Alun dijujai inyo lah galak

Alun diimbau inyo lah datang

Nan bak balam talampau jinak 
Basipaik bak lipeh tapanggang

Umpamo caciang kapanasan

Tagisia labiah bak kanai

Artinya adalah perempuan Simarewan itu suka merasa lebih dari orang lain apakah kecantikannya, kekayaannya, kebaikannya dan lain sebagainya. Baru sedikit saja dibicarakan orang dia sudah merasa bahwa dialah yang paling hebat. Dia mau saja menuruti kata hatinya kemana dia mau tanpa memikirkan akibat terhadap dirinya. Meskipun tidak dilibatkan oleh orang lain kedalam suatu urusan maka dia dia tanpa diajak akan langsung saja mau terlibat kedalam urusan tersebut.

Tuturan pada baris keempat, lima dan enam dapat diartikan bahwa perempuan Simarewan laksana kecoak yang terbakar yaitu kesana melompat kesini melompat. Dia suka bersenda gurau dan membuang buang waktu kesana kemari. Dimana ada keramaian dia akan selalu ada disitu. Dia selalu berdandan kesana kemari. Ketika ada seseorang yang memberi harapan kepadanya maka dia akan langsung percaya saja bahwa harapan itu sudah melebihi kenyataan yang sebenarnya dan dia akan menceritakan harapan itu kepada siapa saja. Tidak ada rahasia yang bisa disimpan oleh perempuan Simarewan ini.

Bait berikutnya adalah:

Kok tumbuah bagaua jo laki-laki

Banyak galak dari kecek

Banyak kucikak jo kucindan

Malu jo sopan tak bapakai

Ereang jo gendeang tak paguno

Nan bak katidiang tangga bingkai

Nan bak payuang tangga kasau

Elok baso nan tak manantu 
Makna dari bait-bait di atas adalah perempuan Simarewan suka bergaul dengan laki-laki dan setiap bergaul dengan laki laki itu dia suka tertawa terbahak bahak tanpa beban. Inti pembicaraan mungkin tidak seberapa tetapi canda dan tawanya berlebihan sekali. Dia tidak merasa malu dan risih bersikap seperti itu meskipun di tengah keramaian.

Dia tidak sadar kalau dia sudah menjadi pembicaraan orang lain karena tingkah lakunya yang tidak sesuai dengan norma yang berlaku. Dia tetap percaya dengan dirinya sendiri tanpa peduli dengan orang lain. Dia tidak menghiraukan apapun penilaian orang terhadap dirinya lagi. Dia tidak lagi berpedoman kepada adat dan syarak yang ada. Dia hanya berbuat sesuka hatinya saja.

Jika kondisinya sudah demikian maka perempuan itu akan jatuh harga dirinya. Dia akan dipandang rendah oleh orang sekitarnya. Seperti ungkapan di atas "bak katidiang tangga bingkai, nan bak payuang tangga kasau” itu artinya orang yang tidak kokoh lagi bentuknya, kepribadiannya, sikapnya dan tutur katanya. Artinya perempuan itu sudah berantakan semuanya sehingga nilainya jatuh sampai ke titik nadir.

Dia tidak lagi memiliki tempat berpijak yang kuat. Budi pekertinya sudah hancur. Agama tidak lagi menjadi pedoman baginya. Ketika kondisinya sudah seperti ini maka dia akan berbaik baik saja kepada semua orang agar mendapatkan perhatian dan mau diajak kemana saja. Dia ingin selalu terlibat dengan siapapun dan ingin merasa dekat dengan siapapun walaupun orang itu tidak membutuhkannya lagi.

\section{KESIMPULAN}

Dengan adanya konsep bundo kanduang sebagai perempuan di Minangkabau semenjak zaman dahulu maka seyogyanya perempuan zaman sekarang kembali menjadikan konsep itu sebagai pedoman dalam bersikap, bertutur kata, bergaul serta berintegrasi sehari hari di lingkungan kita. Seandainya perempuan Minang sudah kehilangan arah maka tidak ada salahnya kita kembali memakai ajaran ajaran yang sudah digariskan oleh budaya kita. 
Sementara konsep perempuan Simarewan adalah konsep perempuan yang tidak boleh diikuti oleh perempuan Minang sampai kapanpun. Simarewan adalah gambaran yang tidak baik dan tidak perlu diikuti. Jika perempuan Minang zaman sekarang sudah banyak yang memakai sifat Simarewan ini maka kembalilah kepada bundo kanduang. Gambaran kehancuran perempuan itu sudah dituangkan semenjak dahulu oleh kebudayaan Minangkabau. Kita yang hidup di zaman sekarang hanya mengikuti saja dan menyesuaikannya dengan zaman. 


\section{DAFTAR PUSTAKA}

Chaer, Abdul. 2012. Sosiolinguistik: Perkenalan Awal. Jakarta: Rineka Cipta

Forsberg, A. 2006. Definitions of Culture: CCSF Cultural Geography: course notes. Retrieved: 2016-04-19.

Harimurti, Kridalaksana 2008. Kamus Linguistik (Edisi Keempat). Jakarta: Gramedia_Pustaka Utama.

Irwan. 2009. Teknik Pasambahan Adat Minangkabau. Batusangkar: STAIN Batusangkar Press

Jamil, Muhammad. 2015. Padusi Minang: Mencari Identitas Bundo Kanduang Ideal Menurut Islam. Bukittinggi: Cinta Buku Agency

Marni, Malay. 2016. Bundo Kanduang di Minangkabau. Avalaible at http://www.kompasiana.com/marnimalay/bundo-kanduangdiminangkabau 5520ef07813311c57619f975

Poedjosoedarmo, S. 2001. Filsafat Bahasa. Surakarta: Muhammadiyah University Press.

Sayuti, M. Dt. Rajo Panghulu. 2009. Kedudukan dan Peranan Bundo Kanduang di Minangkabau.Avalaibleat

https://palantaminang.wordpress.com/2009/09/22/ kedudukan-danperanan-bundo-kanduang-di-minangkabau/

Sudaryanto. 1993. Metode Linguistik: Metode dan Aneka Teknik Analisis Bahasa. Yogyakarta: Duta Wacana University Press

Sumarsono. 2007. Metode Sosiolinguistik: Yogyakarta: Duta Wacana University Press

UNESCO. 2002. Universal Declaration on Cultural Diversity, issued on International Mother Language Day, February 21, 2002. Retrieved: 2016-06-23. 